\title{
Design an Improved System to Control the Computer Temperature
}

\author{
${ }^{\text {a HANI. K. AL-MOHAIR, }{ }^{b} H U S S I E N ~ A . ~ A L H A D A D D ~}$ \\ Computer and Information Technology Dammam Community College King Fahd University of Petroleum \\ and Minerals, 31261, \\ KFUPM Dhahran, Eastern Region, Saudi Arabia \\ E-mail: ahanik@kfupm.edu.sa, ${ }^{\text {b201620204@dcc.kfupm.edu.sa }}$
}

\section{INTRODUCTION}

\begin{abstract}
Temperature is one of the most significant problems that computer users face, especially the users who deal with works that required highperformance processing such as gamers and designers. The traditional PC heat detection methods depend on the information of the CPU and the user should go through a long procedure to check the heat or by installing some third-party programs and in the end, he has to take the action manually. Although some researchers have been talked about the temperature controllers, no system used both software and hardware to control the PC temperature, also there is no consensus on the quick and efficient methods to protect the $\mathrm{PC}$ from the overheating problem. The proposed system improved the current solutions by providing better performance in terms of quick responses for safety protection. This paper proposes a novel system for controlling the $\mathrm{PC}^{\prime} \mathrm{s}$ temperature to increase the safety of computer users.
\end{abstract}

Key-words: Heating System, Computer temperature, Computer Safety
Nowadays, the performance of computers has been continuously developed to achieve various technological demands that utilizing a computer for daily activity. Therefore, higher heat temperature is simply occurring on the electronic components used for a PC such as a chip laid on the Motherboard and the CPU. The cooling techniques have been significant effect to decrease the heat rising [1]. The cooling technique has been continuously developed to achieve various applications. Although, there are different technologies to reduce the temperature of the PC,

Still there is a need for a quick and automatic response

to shut down the PC for any up normal temperature to protect the $\mathrm{PC}$ and its hardware.

Some researchers focused on the environment of the $\mathrm{PC}$ to control the area around the PC such as the room temperature. [2]. designed and developed the fan speed control system to control the room temperature. The temperature sensor was carefully chosen to gauge the room temperature. Besides, the PIC microcontroller had been used to control the fan speed using the PWM. 
Many researches focusing on automatic temperature control system application in different fields will gain the benefits. For examples, an automatic temperature controller for multi element array hyperthermia systems [3] \& [4] designed of a room temperature and humidity controller using fuzzy logic. The proposed model consists of two fuzzy logic controllers to control temperature and humidity respectively.

Temperature Control System using PID controller which is applied to a room in order to monitor the desired temperature at all times designed and implemented by [5]. This study includes real time temperature control using a PID controller implemented on a microcontroller. A temperature control system is designed based on AT89C51 single-chip microcomputer (Abbreviation SCM, MCU) that is able to monitor computer room temperature [6]

The design and simulation of an automatic system for temperature control using embedded system in order to automatically control of multi appliances depend on the temperature value is done by [7]. Control circuitry for controlling the operation of the fan subsystem includes a thermistor for sensing the temperature within the housing of the computer system is designed by [8]. Temperature Sensors A, B, and C are arranged near a CPU,HDD, and PC card controller, and monitor changes in temperature of these devices. the device to be cooled is determined by identifying that temperature Sensor, and cooling is done at power Suited to the tempera ture characteristics of the determined device[9].
Therefore, monitoring the PC and room temperature is crucial for computer users, IT administrators, and companies. It will assist the PC users in making automatic decisions when the PC temperature is high, which will lead to achieving a new gate to the PC Safety field.

\section{METHODOLOGY AND RESULTS}

The main objectives of this system are to:

1. Control the PC temperature automatically.

2. Alert the user

3. Increase the safety of PCs

4. Open the door for research in safety in the IT field.

A summary of the requirements used in this proposed system shows in the following figure. These Components are mixed between the hardware and the software, both technologies are used to build this proposed system. This system is designed and developed from scratch.

The 3D printer is used to create the system cabinet of the proposed system.

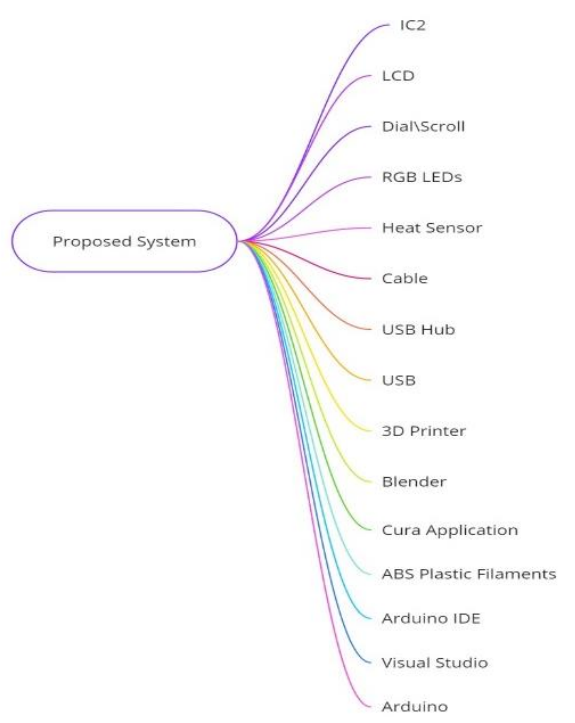

Figure 1: The Proposed System Main Components 
The function of each component is shown in the following table.

Table 1: system components' function

\begin{tabular}{|c|c|}
\hline Item & Function \\
\hline Arduino & $\begin{array}{l}\text { A Microcontroller (Open-source electronic prototyping platform enabling users to create } \\
\text { interactive electronic objects). }\end{array}$ \\
\hline IC2 & A connector between the screen and Arduino \\
\hline LCD & Display the menu setting and shows the temperature of the PC \\
\hline DiallScroll & Navigate among menu pages \\
\hline RGB & Navigate between menu pages ( Color-Based) \\
\hline $\begin{array}{l}\text { Heat } \\
\text { Sensor }\end{array}$ & $\begin{array}{l}\text { Measure the temperature of the PC, and send the data to Arduino, then to the Proposed } \\
\text { Application }\end{array}$ \\
\hline Cables & for connecting Arduino Parts and to send the data \\
\hline USB Hub & Provide the electricity to the components \\
\hline USB & Connect the Arduino to the PC \\
\hline 3D Printer & Build and print the case of the proposed system \\
\hline Blender & $\begin{array}{l}\text { A free and open-source 3D computer graphics software toolset used for creating animated } \\
\text { films, visual effects, art, 3D printed models }\end{array}$ \\
\hline Cura & Open source slicing application for 3D printers. To change Blender File format \\
\hline $\begin{array}{l}\text { ABS } \\
\text { Plastic } \\
\text { Filaments }\end{array}$ & Material used by the 3D printer \\
\hline $\begin{array}{l}\text { Arduino } \\
\text { IDE }\end{array}$ & To program Arduino \\
\hline Visual & To program the proposed system PC Application \\
\hline
\end{tabular}




\section{SYSTEM ASSEMBLY}

To start assembling the proposed system, the circuit diagram is created as shown in figure 2. First, all the required components are collected, second, the components are soldered together as shown in figure 2. Third, the Arduino controller is programmed to read the sensor values and send data to the RGB LEDs. Finally, the LED's color will be changed automatically based on the heating status of the PC. If the PC is in the cold or normal temperature, so the LED color will be blue, otherwise, the PC temperature will be high and the LED color will be red. More than that if the PC got overheated The LED will be blinking in red color. In this case, the PC user or the server if we are using this system in the server room will know that the PC is in a dangerous situation and he should take the necessary actions. Moreover, the LCD screen will show the current temperature value and that value will help the user to see the temperature without opening the application. The real circuit diagram with the case from inside which is printed using the $3 \mathrm{D}$ printer will be shown in Figure 3.

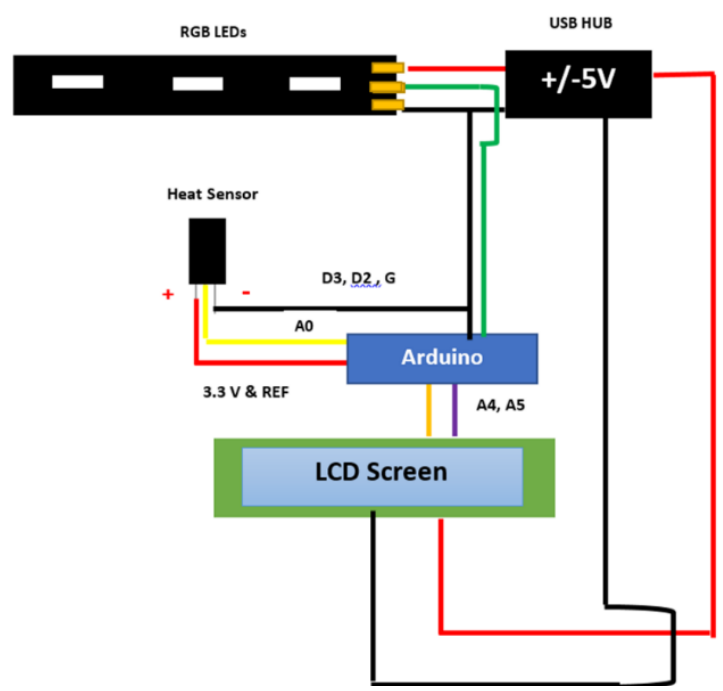

Figure 2: The Proposed System Circuit Diagram

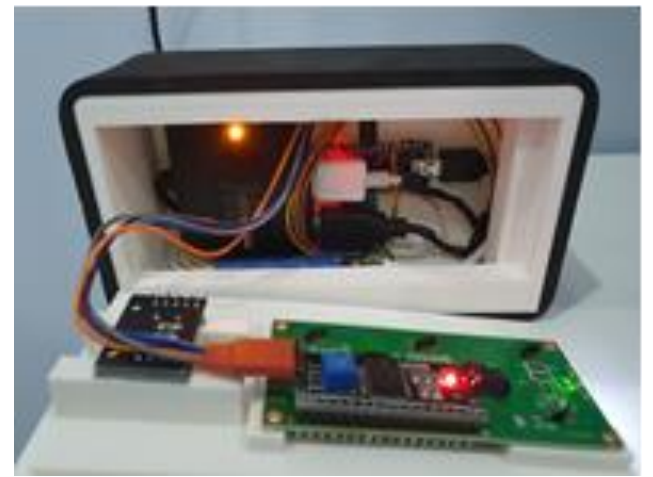

Figure 3: The Real Circuit Diagram
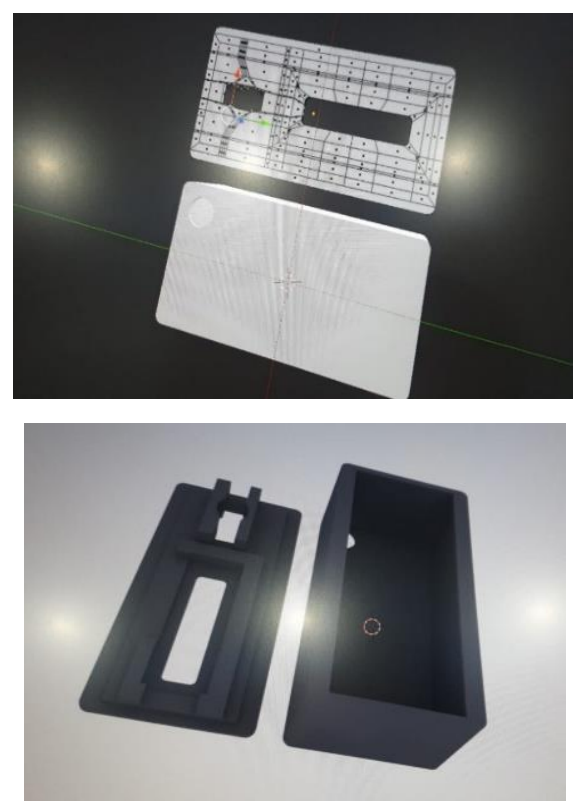

Figure 4: Designing of the case

In this proposed system we thought to make the system as a product, as an electronic device, so any computer user can use it to protect his PC from heating issues especially the people that work in designing or interesting in gaming. The case for the proposed system is designed using the Blender 3D printer as shown in figure 3 . Cura application is used to change the format to fit the format used in the printer used for designing, see figure 4. Finally, we printed the case and after some modification and adjustment we got the case as figure 5: 


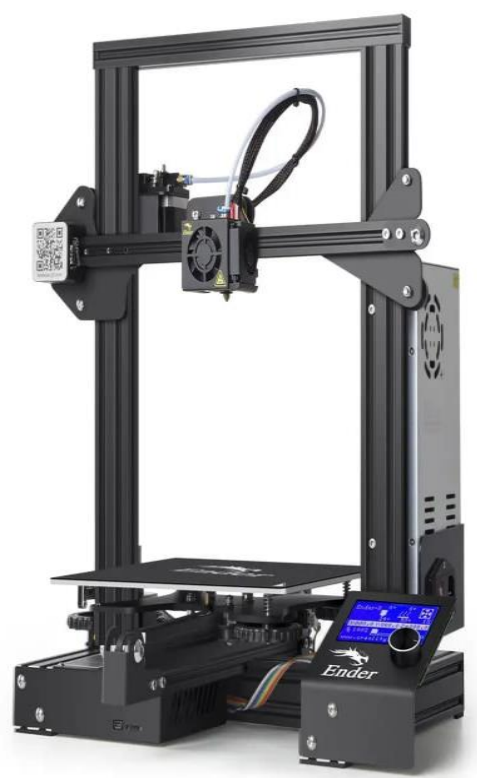

Figure 4: The Blender 3D printer

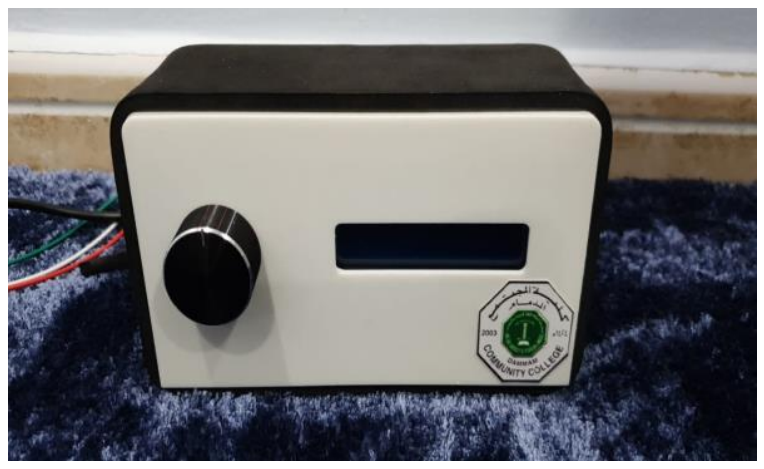

Figure 5: The Proposed System inside the printed case

\section{MENU SETTINGS}

The menu setting is designed to set the settings of the proposed system such as setting the LED lighting to the desired temperature, we soldered the controller buttons to connect them to the Arduino, and then we started working on Arduino software to make a built-in system within the Arduino.
The user will be able to set the desired color for each temperature, for example, he can select the Green color if the PC temperature is cold, and if the $\mathrm{PC}$ is hot and reaching a critical point the LED will change to the Red color. The screen will show the menu settings, and the user will navigate between the options by rotating the dimmer switch right or left. The following figure ( Figure 6 ) will give a clear idea about the purpose of the menu settings.
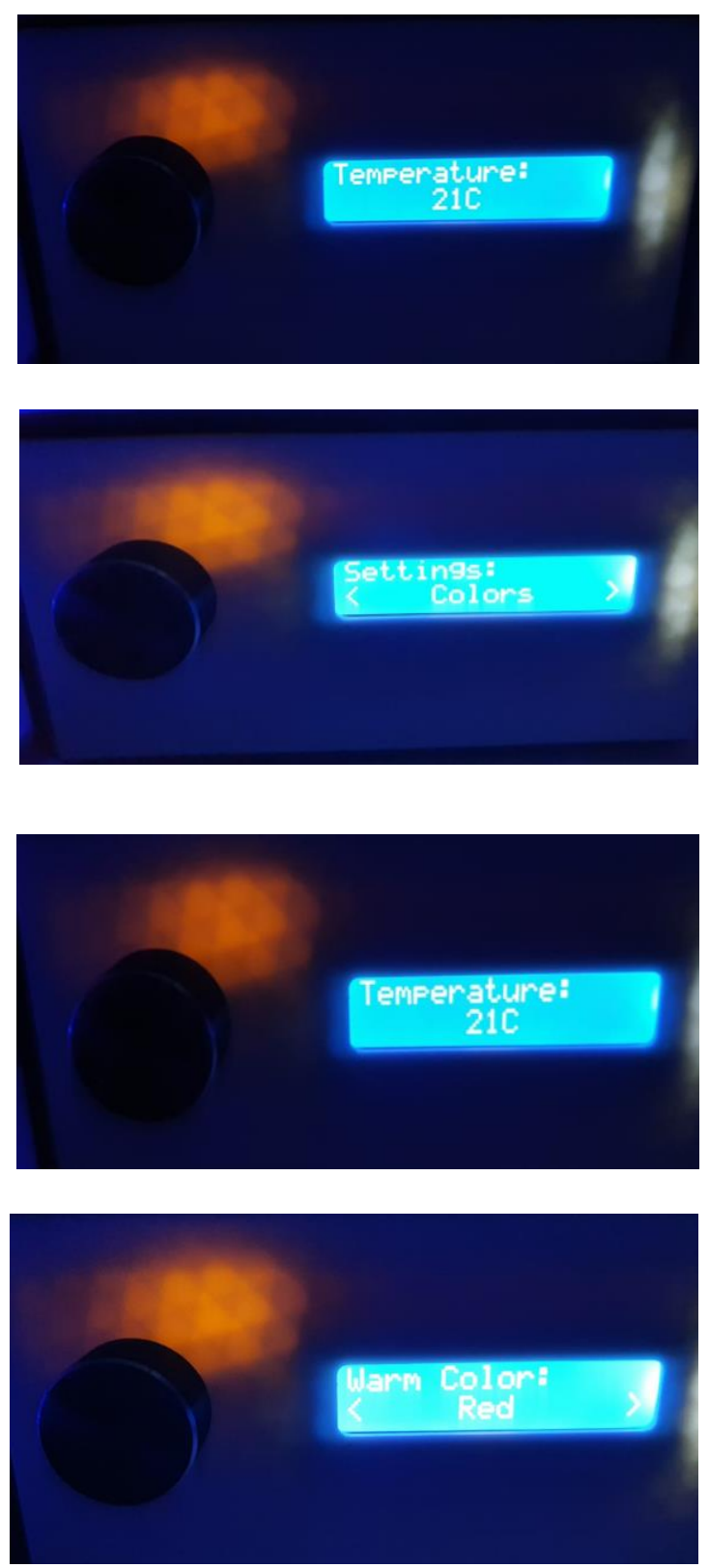

Figure 6: Menu settings 


\section{PC APPLICATION}

The designed application contains the same functions as the device menu. This application is designed using the visual studio which will be easy to use and friendly for all computer users. Using this application, the user can check the PC temperature and change the setting of the RGB lighting, also setting the maximum and minimum temperature for the PC, furthermore, he can apply automatic shutdown to the Computer. And adjust the fan settings as shown in figure 7 .

As can see from the figure, the user will see the PC temperature live which is one of the best features of this device, it will be automatically change based on the temperature of the PC and will be noticed by the user clearly.

The auto-shutdown button is also added to the application as the necessary action should be taken by the user for emergency issues. This feature will make this device novel and unique because it will be easy for the user to solve the problem and to avoid any incidents caused by the high temperature.

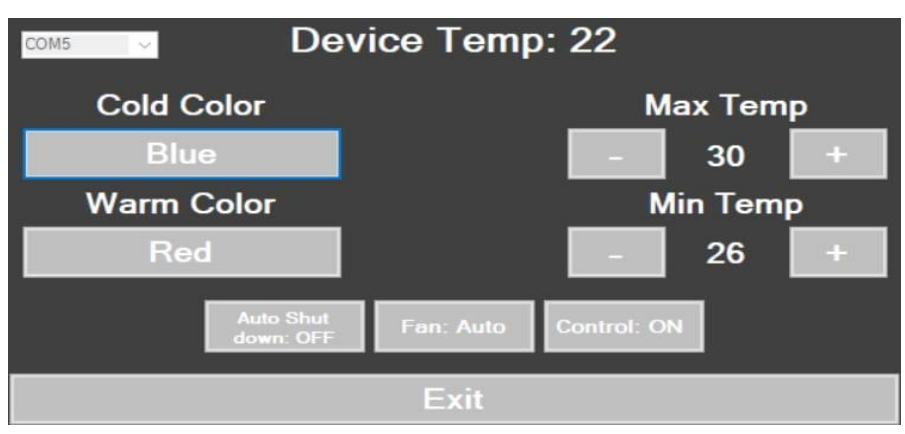

Figure 7: PC Application

\section{CONCLUSION}

The presented developed system is a promising starting point for the field of PC safety protection. The system is designed from scratch successfully using an Arduino controller and other electronic components, 3D printer is used perfectly to design the prototype of the proposed system to start the idea of marketing this type of device that will create a new path for safety technology. Moreover, an application is designed to have full control and quick access to control and solve the $\mathrm{PC}$ overheating issues.

\section{5( ) ( 5) $1 \&(6 \square$}

[1]Songkran Wiriyasart, Chootichai Hommalee, Paisarn Naphon. (2019). Thermal cooling enhancement of dual processors computer with thermoelectric air cooler module. Case Studies in Thermal Engineering 14.

[2] Mustafa Saad, Hossam Abdoalgader, and Muammer Mohamed. (2014). Automatic Fan Speed Control System Using Microcontroller . th Int'l Conference on Electrical, Electronics \& Civil Engineering (ICEECE'2014) Nov. 27-28, 2014 Cape Town (South Africa)

[3] Jessi E. Johnson, , Paolo Maccarini, Daniel Neuman and Paul Stauffer. (2006) "Automatic Temperature Controller for Multielement Array Hyperthermia Systems," IEEE Transactions on Biomedical Engineering, pp. 1006-1015, .

[4]Tarun Kumar Das, Yudhajit Das. (2013). Design of A Room Temperature And Humidity Controller Using Fuzzy Logic, American Journal of Engineering Research (AJER) e-ISSN : 23200847 p-ISSN : 2320-0936 Volume-02, Issue-11, pp-86-97

[5] Sudhir Ranjan; Abhishek Sharma; Puneet Chaudhary (2014). An effective temperature controller system using PID mechanism. 2014 Innovative Applications of Computational Intelligence on Power, Energy and Controls with their impact on Humanity (CIPECH).

[6]Kunliang $\mathrm{Xu}$ (2015). Design of Temperature Control System for Computer Rooms Based on AT89C51 Single-chip, CHEMICAL ENGINEERING TRANSACTIONS, VOL. 46.

[7] Jabbar Shaati Jahlool. (2017). Design and Simulation of Automatic Temperature Control and Alert System Based PIC16F887, International Journal of Informatics and Communication Technology (IJ-ICT) Vol. 6, No. 2, August 2017, pp. 95 104

[8] James S. Dinh, Spring; George K. temperature dependent fan control circuit for personal computer, United States Patent, Patent Number: 5,526,289

[9] Shinichi Suzuki; Hiroaki Yokomichi, computer system and its cooling control method, United States Patent, Patent Number: 6,134,667.

\section{Creative Commons Attribution License 4.0 (Attribution 4.0 International, CC BY 4.0)}

This article is published under the terms of the Creative Commons Attribution License 4.0

https://creativecommons.org/licenses/by/4.0/deed.en_US 